\title{
The social representation of telecommunications
}

\author{
Leopoldina Fortunati · Anna Maria Manganelli
}

Published online: 11 March 2008

(C) Springer-Verlag London Limited 2008

\section{Erratum to: Pers Ubiquit Comput DOI 10.1007/s00779-006-0139-7}

Unfortunately, two errors occurred in the text of this article. The Abstract and Keywords were missing. The complete text is given below.

\begin{abstract}
For a long time now sociologists have spoken of the domestication of information and communication technologies (ICTs) to indicate their process of integration in everyday life. In this paper, we wish to deal with a crucial aspect of this process, which is the domestication of ICTs at the socio-cognitive level. Our aim is to reconstruct how these technologies have been metabolised in the system of
\end{abstract}

social thought, and the way in which they have been integrated conceptually. At the same time, we wish to propose the methodology of social representations as being particularly suitable for investigating the social meaning of telecommunications. In the course of a telephonic survey of a sample of Italian population of 2,100 persons, 210 interviewees were asked to associate two terms with 10 cue words: telecommunications, fax, television, telephone, computer, mobile phone, radio, video-recorder, stereo, newspapers. The associations obtained were analysed by factor analysis of simple correspondences.

\section{Keywords}

Telecommunications $\cdot$ Social representation $\cdot$ Media $\cdot$ ICT . Domestication $\cdot$ Fashion

The online version of the original article can be found under doi:10.1007/s00779-006-0139-7.

The research has been designed and discussed in all its parts by both the authors. As the writing of the paper, the Introduction, the Structure of the field of Representation and the Conclusions were written by Leopoldina Fortunati; Method, Results, Similarities between Communicative Technologies, Field of representation were written by Anna Maria Manganelli.

L. Fortunati $(\bowtie)$

Department of Economy, Society and Geography,

University of Udine, Padova, Italy

e-mail: fortunati.deluca@tin.it

\section{A. M. Manganelli}

Department of General Psychology,

University of Padova, Padova, Italy

e-mail: annamaria.manganelli@unipd.it 